\title{
A Time Course Study of Production of Virulence Factors by Biofilms of Pseudomonas aeruginosa
}

\author{
Rahul Mittal $^{1,2 *}$, Saroj Sharma ${ }^{2}$, Sanjay Chhibber $^{2}$, Kusum Harjai ${ }^{2}$ \\ ${ }^{1}$ Division of Infectious Diseases, Childrens Hospital Los Angeles, Los Angeles, CA, USA \\ ${ }^{2}$ Department of Microbiology, Panjab University, Chandigarh, INDIA \\ *Corresponding Author: \\ Dr Rahul Mittal \\ Division of Infectious Diseases, MS\#51 \\ Childrens Hospital Los Angeles, \\ 4650 Sunset Boulevard \\ Los Angeles, CA, 90027, USA \\ Telephone: 323-361-5809 \\ E-Mail: ramittal@chla.usc.edu; rahul_mittal20022@yahoo.com
}

Received: 1 February 2009; | Revised: 18 March 2009; | Accepted: 2 April 2009

\begin{abstract}
Pseudomonas aeruginosa is an epitome of opportunistic pathogens. It is the third most common pathogen associated with hospital acquired catheter associated urinary tract infections (CAUTIs). This pathogen forms biofilms on the surface of indwelling catheters which are resistant to antimicrobial agents as well as to host defense mechanisms leading to chronicity and recurrence of infections. In the present study, elaboration of virulence factors by immature and mature biofilm cells of $P$. aeruginosa was assessed in vitro. It was observed that with increase in time period of biofilm generation from 1 to 4 day (immature biofilms) there was increase in elaboration of majority of virulence traits. However 5 day old biofilms (mature biofilms) were least producers of all the virulence determinants which continued till $7^{\text {th }}$ day. Implications of these findings in relation to urinary tract infections caused by biofilms of $P$. aeruginosa have been discussed.
\end{abstract}

Keywords: Pseudomonas aeruginosa; Biofilms; Urinary tract infections; Virulence factors.

\section{Introduction}

Urinary tract infections (UTIs) account for $30-40 \%$ of all nosocomial infections out of which $90 \%$ of these nosocomial UTIs are associated with urinary catheters. The major problems of the catheter associated UTIs (CAUTIs) are morbidity, sizeable overall health care costs and mortality [1].
The severity of CAUTIs varies from acute symptomatic pyelonephritis to chronic pyelonephritis with a potential to lead to renal failure and death. Pseudomonas aeruginosa has emerged as a major opportunistic pathogen which accounts for about $14 \%$ of all hospital acquired UTIs [2]. Although epidemiological studies have correlated the association of $P$. aeruginosa with () 2009 by NWPII. All rights reserved. 
CAUTIs, but understanding of pathogenesis of such infections is still not very clear.

The virulence of $P$. aeruginosa is multifactorial and has been attributed to cellassociated factors like alginate, lipopolysaccharide (LPS), flagellum, pilus and non-pilus adhesins as well as with exoenzymes or secretory virulence factors like protease, elastase, phopholipase, pyocyanin, exotoxin $\mathrm{A}$, exoenzyme $\mathrm{S}$, hemolysins (rhamnolipids) and siderophores [3-6]. These factors have been shown to play an important role in pathogenesis of $P$. aeruginosa induced infections like respiratory tract infections, burn wound infections and keratitis [7-11]. In addition to elaboration of virulence factors, P.aeruginosa has a tendency to form biofilms on the surface of indwelling catheters in catheterized patients. Growth of $P$. aeruginosa begins in the form of microcolonies, which later coalesce together to form biofilms [12-14]. Biofilms are resistant to antimicrobial agents as well as to host defense mechanisms and hence are difficult to eradicate. Biofilms contribute towards pathogenicity of $P$. aeruginosa as these often lead to persistent and recurrent infections [15-17]. In the present investigation, we compared the elaboration of virulence factors by immature and mature biofilms. Extrapolation of available information will help in understanding pathogenesis of CAUTIs caused by biofilms of $P$. aeruginosa.

\section{Materials and Methods}

Organisms: Five urinary isolate of $P$. aeruginosa PA1, PA2, PA3, PA4 and PA5 isolated from hospitalized patient having complicated UTI and serotyped as O4, O3, O6, O7/8 and O11 respectively by Laboratory of Healthcare Associated infection, London, employed in earlier studies [18-21], were used. These strains produced most of the recognized virulence factors like alginate, protease, elastase, phopholipase C, hemolysin, pyochelin and pyoverdin. In addition, a standard strain of $\mathrm{P}$. aeruginosa, $\mathrm{PAO}$, producing the above mentioned virulence factors was obtained from Dr. Barbara H. Iglewski, University of Rochester, New York (USA). All the strains were maintained on nutrient agar stabs at $4^{\circ} \mathrm{C}$ and in glycerol stocks at $-70{ }^{\circ} \mathrm{C}$.
Generation of biofilm cells: The method of Ladd et al., [22] as standardized in our laboratory by Mittal et al., [23] was followed for generation of biofilms. Foley's catheter (Bardia) was cut into $1.0 \mathrm{~cm}$ pieces and put into the nutrient broth medium. These were inoculated with $100 \mu \mathrm{l}$ of overnight culture and incubated at $37^{\circ} \mathrm{C}$. Every 24 $\mathrm{h}$ catheter pieces were removed from each flask, rinsed three times with phosphate-buffer saline (PBS, pH 7.2) and transferred to the new flask containing fresh medium until day 7. On each day, catheter pieces were rinsed three times with PBS to remove adherent bacteria and sliced longitudinally into equal halves. Cells were removed from the surface of catheter pieces by scrapping the inner surface with a sterile scalpel blade. The dispersed sample was then centrifuged, washed 3 times with PBS and then suspended in 1 $\mathrm{ml}$ PBS. Bacterial concentration was confirmed by viable counts. Crystal violet staining of the biofilm cells was done following the method of Walker et al., [24]. Briefly, biofilms were generated in 96 well microtiter plate, stained with crystal violet and then washed and eluted with ethanol followed by absorbance of the sample at $600 \mathrm{~nm}$.

Preparation of cell free supernatant (CFS): Culture supernatants were collected from biofilm cells on day 1 to day 7 after adjusting the absorbance $\left(\mathrm{A}_{540}\right)$ to 1.0 for estimation of virulence factors.

Alginate determination: Alginate in the culture supernatant was precipitated with an equal volume of $2 \%(\mathrm{w} / \mathrm{v})$ cetylpyridinium chloride. Amount of alginate was determined using a borate/ carbazole method with D-mannuronate lactone used to calibrate a standard curve according to the method of Mathee et al., [25].

Uroepithelial cell (UEC) adhesion assay: UEC adhesion assay was performed following the method of Mittal et al., [18]. Urine samples from healthy females in the age group between 20 to 25 years were screened for regular shedding of uroepithelial cells. Early morning pooled urine samples of four healthy females $(300 \mathrm{ml}$ from each subject) who were regular shedders were used for the collection of UECs. Only the females who were not taking any antibiotics or other supplements were included in this study. Throughout the study period, urine was collected 
from these volunteers. Urine was centrifuged at $2000 \mathrm{rpm}$ for 15 minutes at $4^{\circ} \mathrm{C}$ and UECs were washed thrice with PBS, $\mathrm{pH}$ 7.0. Sediment was suspended in PBS. A drop of trypan blue dye was added to the final suspension to identify dead UECs. The cell count of the viable cells was adjusted to 105 cells per $\mathrm{ml}$ using a haemocytometer after staining with $0.1 \%$ trypan blue. An adhesion assay mixture consisting of 1 $\mathrm{ml}$ each of bacterial cells and UECs was incubated at $37^{\circ} \mathrm{C}$ for $1 \mathrm{~h}$. After centrifugation and a minimum of three washings to remove unattached bacteria, smears were prepared and stained with Giemsa stain. Bacteria adhering to 30 UECs were counted, and the average number of bacteria adhering per UEC was calculated.

Protease production: For proteolytic activity, culture supernatants were diluted in $10 \mathrm{mM}$ Tris $(\mathrm{pH} \mathrm{7.5)}$ and incubated with $15 \mathrm{mg}$ hide powder azure (Sigma Chemical Company, USA) at $37^{\circ} \mathrm{C}$ for $1 \mathrm{~h}$. Absorbance was measured at $595 \mathrm{~nm}$ and results were expressed in units per liter (U/l) [26].

Elastase production: Elastolytic activity was measured by using elastin-congo red (Sigma Chemical Company, USA) as substrate [26]. Optical density was taken at $495 \mathrm{~nm}$ and results were expressed in units per liter (U/l).

Phopholipase C (PLC) production: PLC activity was measured spectrophotometrically at $405 \mathrm{~nm}$ using p-nitrophenylphosphorylcholine (PNPC, Sigma Chemical Company, USA) as substrate and results were expressed in units per liter (U/l) [7].

Pyochelin and Pyoverdin estimation: Pyochelin was estimated in $1 \mathrm{ml}$ of culture supernatant, mixed with $1 \mathrm{ml}$ each of $0.5 \mathrm{~N} \mathrm{HCl}$, nitrite molybdate reagent and $1 \mathrm{~N} \mathrm{NaOH}$. Final volume was made to $5 \mathrm{ml}$ with double distilled water and absorbance was read at $510 \mathrm{~nm}$ [23]. For pyoverdin estimation, fluorescence of $3 \mathrm{ml}$ of supernatant ( $\mathrm{pH}$ adjusted to 2.0 and extracted with ethyl acetate) was measured at $460 \mathrm{~nm}$ (Relative fluorescence, RF) while the samples were excited at $400 \mathrm{~nm}$ in a Gibson Spectro Gloflourometer.

\section{Hemolysin Production: Quantitative} determination of cell free and cell bound hemolysin was done using $2 \%$ suspension of washed human erythrocytes following the method of Linkish and Vogt, [27]. The amount of hemolysin released was determined using lyophilized hemoglobin to calibrate a standard curve. Results were expressed in hemoglobin released $\mathrm{mg}$ per $\mathrm{ml}(\mathrm{Hb}$ released $\mathrm{mg} / \mathrm{ml})$.

\section{Results}

In the present study, 5 uroisolates and 1 standard strain (PAO) of $P$. aeruginosa were used for the generation of biofilms on the catheter surface. Biofilm formation was confirmed by viable cell counting and crystal violet staining. Viable cell counts (log CFU) increased with increase in days of incubation from day 1 to 5 , indicating biofilm formation of all the strains. Maximum cell count was observed in 5 day old biofilms of $P$. aeruginosa. Slight decrease in viable cell count was observed in $6^{\text {th }}$ day and $7^{\text {th }}$ day old biofilm cells of all the strains (Fig. 1A). Crystal violet staining assay of biofilm cells also revealed maximum biofilm density on $5^{\text {th }}$ day of biofilm generation followed by decrease in density on $6^{\text {th }}$ and $7^{\text {th }}$ day of biofilm formation (Fig. 1B).

Biofilm cells of these 5 uroisolates and a standard strain (PAO) were then screened for the elaboration of virulence factors. Alginate production by biofilm cells of $P$. aeruginosa was assessed from day 1 to day 7 of biofilm formation in terms of concentration of alginic acid $(\mu \mathrm{g} / \mathrm{ml})$. Maximum production of alginate was seen by 4 day old biofilm cells followed by a decline in 5 day old biofilm cells (Fig. 2). A marginal increase in alginate production was observed in 7 old biofilm cells of all the strains.

Adherence of biofilm cells of $P$. aeruginosa to UECs was checked from day 1 to day 7 of biofilm formation. Adherence of 4 day old biofilm cells to UECs was found to be maximum followed by reduction in adherence of 5 day old biofilm cells in 5 strains of $P$. aeruginosa (Fig. 3). In one of the strain PA 2, maximum adherence of 5 day old biofilm cells to UECs was seen which was followed by a similar pattern of decreased adhesion with 6 and 7 day old biofilm cells (Fig. $3)$. This decrease in adherence of $P$. aeruginosa may be attributed to decrease in elaboration of alginate which is an important adhesin that plays an important role in adhesion to UECs.

(C) 2009 by NWPII. All rights reserved. 


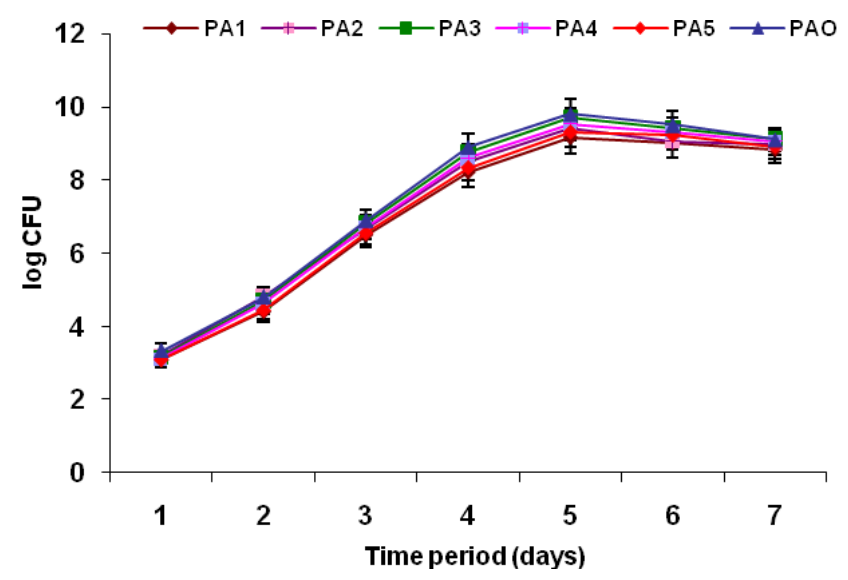

Fig. 1A. Viable cell counts of biofilm cells of $P$. aeruginosa

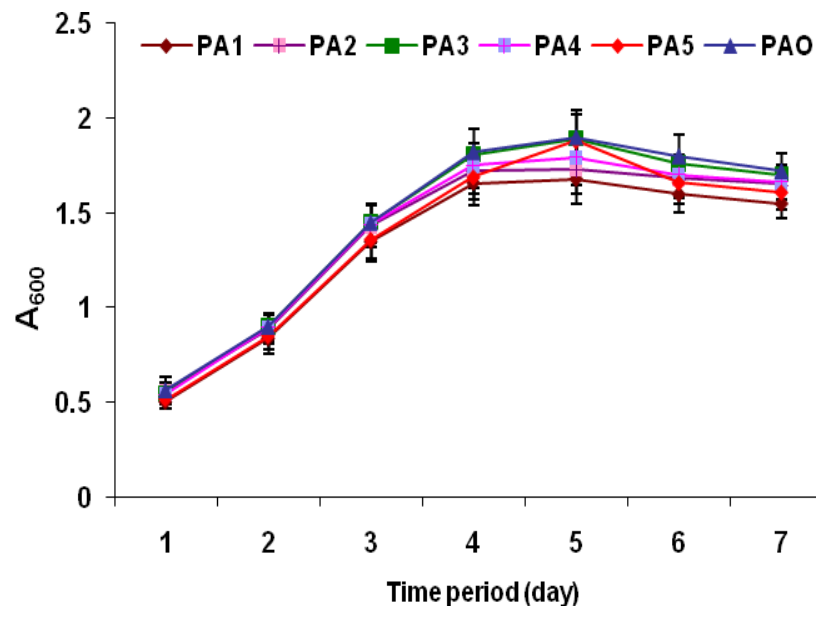

Fig. 1B. Quantitation of biofilm cells of $P$. aeruginosa by crystal violet staining.

In the present study, variation in the elaboration of exoenzyme production by immature and mature biofilms was observed. Peak production of protease was observed in 3 day old biofilm cells of 2 strains of $P$. aeruginosa (PA1 and PA2) whereas it was maximum in 4 day old biofilm cells in the remaining 4 strains of $P$. aeruginosa. Decrease in protease production was observed with all the strains of $P$. aeruginosa in 5 day old biofilm cells which remained almost constant till $7^{\text {th }}$ day. (Fig. 4). Elaboration of elastase increased with time and maximum production was seen in 4 day old biofilm cells followed by a decline in 5 day old biofilm cells which remained almost constant with 6 and 7 day old biofilm cells (Fig. 5). With increase in time period of biofilm formation from day 1 to day 4 increase in PLC production was observed with peak production observable in 4 day old biofilm cells of all the strains of $P$. aeruginosa (Fig. 6). Decrease in PLC production was observed in 5 old biofilm cells of $P$. aeruginosa which remained almost constant with 6 and 7 day old biofilm cells.

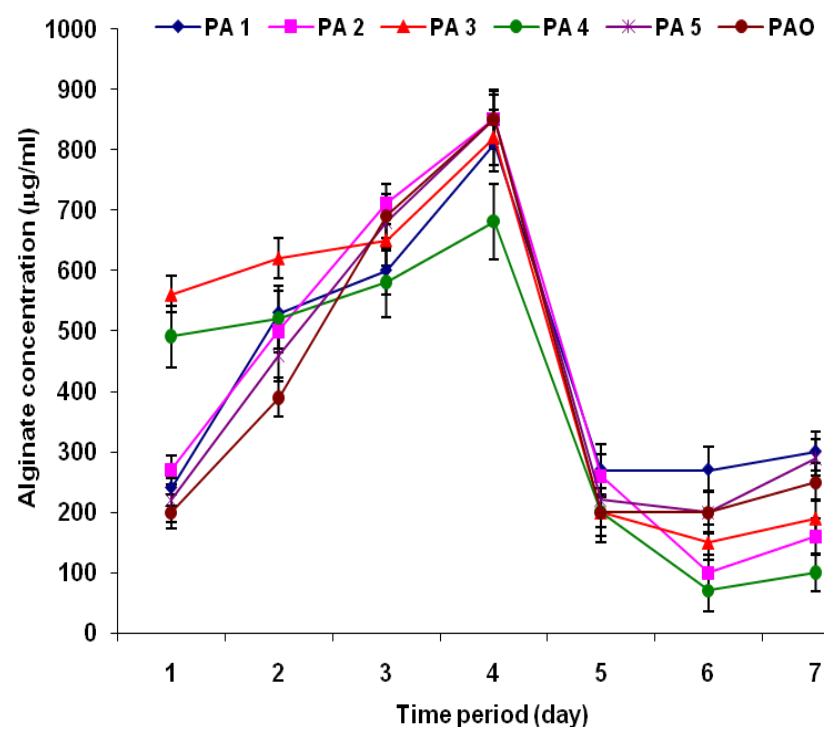

Fig. 2 Alginate production by biofilm cells of $P$. aeruginosa.

Pyochelin production was found to be maximum in 1 day old biofilm cells followed by immediate decline in 2 day old biofilm cells. It further showed increase in 3 and 4 day old biofilm cells in 5 strains followed by decrease in 5 day old biofilm cells which remained constant in 6 and 7 day old biofilm cells. One of the strain showed slight decrease in pyochelin production till $3^{\text {rd }}$ day with increase observed on $4^{\text {th }}$ day followed by decrease on $5^{\text {th }}$ day after which similar pattern was observed (Fig. 7A). Pyoverdin production by biofilm cells of $P$. aeruginosa was checked by relative fluorescence. Maximum production of pyoverdin was observed in 4 day old biofilm cells followed by a decline in pyoverdin production in 5 day old biofilm cells which further declined in 6 day old and remained constant in 7 day old 
biofilm cells (Fig. 7B). This pattern was observed in all the strains of $P$. aeruginosa.

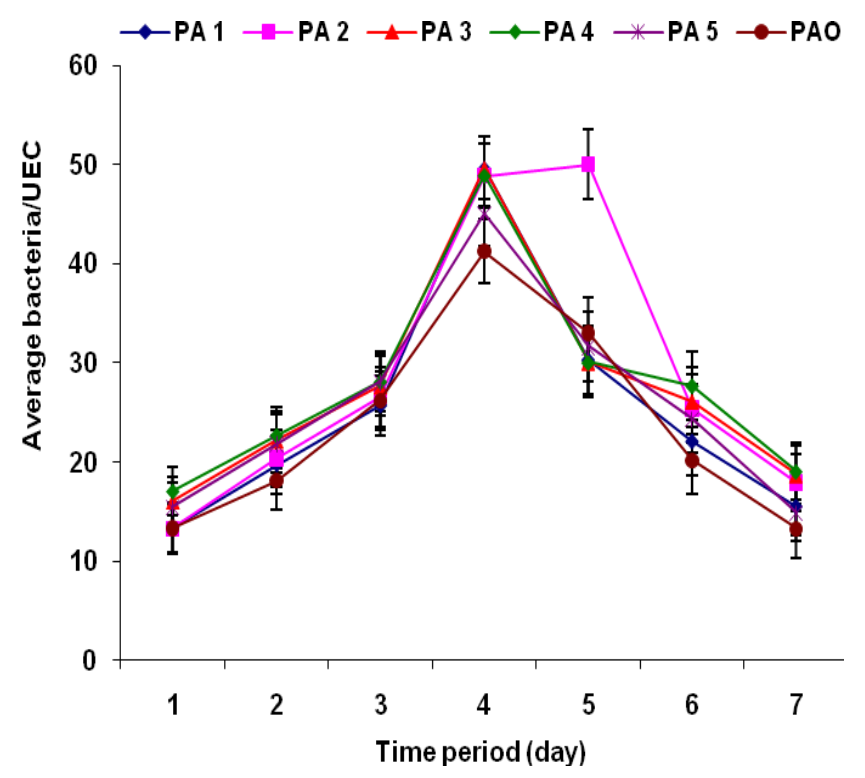

Fig. 3: Uroepithelial cell adherence of biofilm cells of $P$. aeruginosa

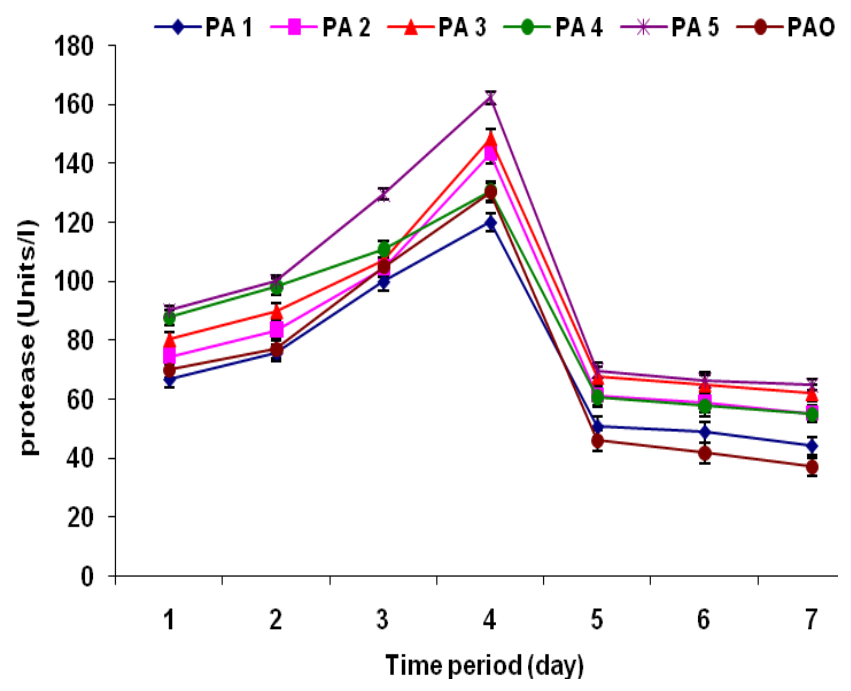

Fig. 4. Protease production by biofilm cells of $P$. aeruginosa

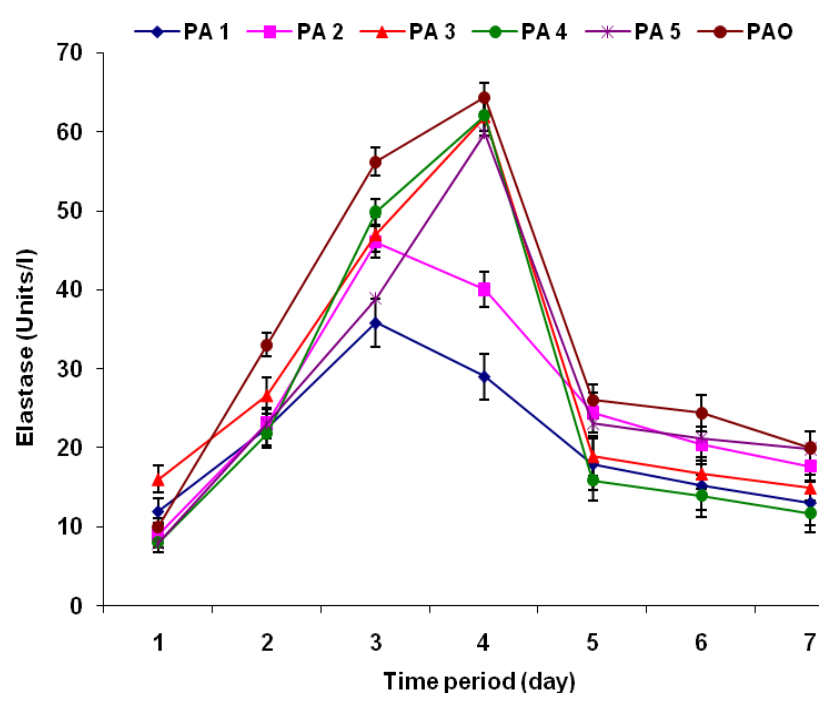

Fig. 5. Elastase production by biofilm cells of $P$. aeruginosa

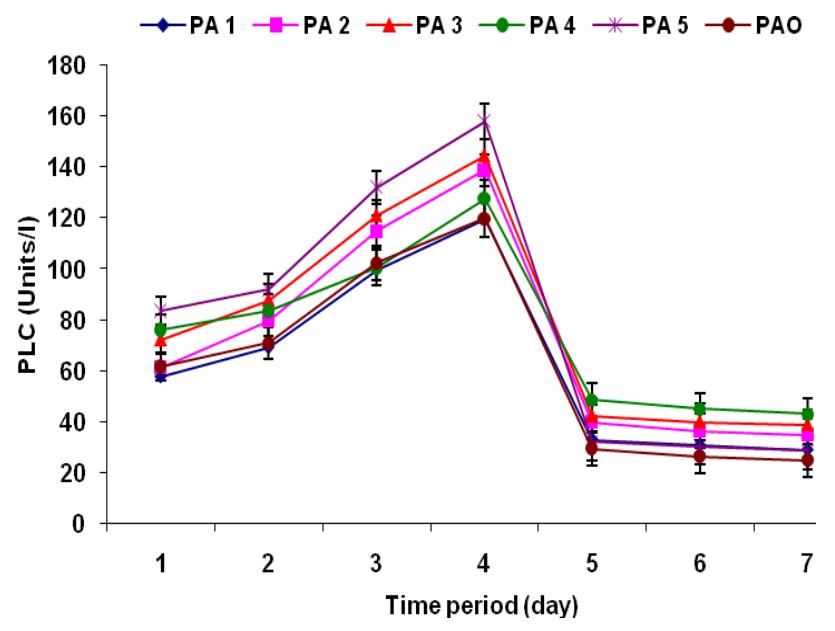

Fig. 6. Phopholipase $\mathrm{C}$ production by biofilm cells of $P$. aeruginosa

Results of cell free hemolysin assay as assessed on the basis of lysis of human red blood cells (hRBCs) and release of hemoglobin by the supernatants of 1-7 day old biofilm cells of $P$. aeruginosa, showed that with increase in age of biofilms there was increase in production of cell free hemolysin with maximum release of hemoglobin observed with supernatant of 4 day old biofilm cells followed by decline with 5 day old mature biofilm cells (Fig. 8A). A slight 
increase in cell free hemolysin production was again observed in 6 day and 7 day old biofilm cells of all the strains. Maximum production of cell bound hemolysin by biofilm cells of $P$. aeruginosa was observed in 3 day old biofilm cells of 4 strains of $P$. aeruginosa whereas in case of other 2 strains, peak production was observed in 4 day old biofilm cells. In 5 day old mature biofilm cells, there was decrease in production of cell bound hemolysin for all the strains of $P$. aeruginosa (Fig. 8B). An increase in cell bound hemolysin production was observed in 6 and 7 day old biofilm cells.

A.

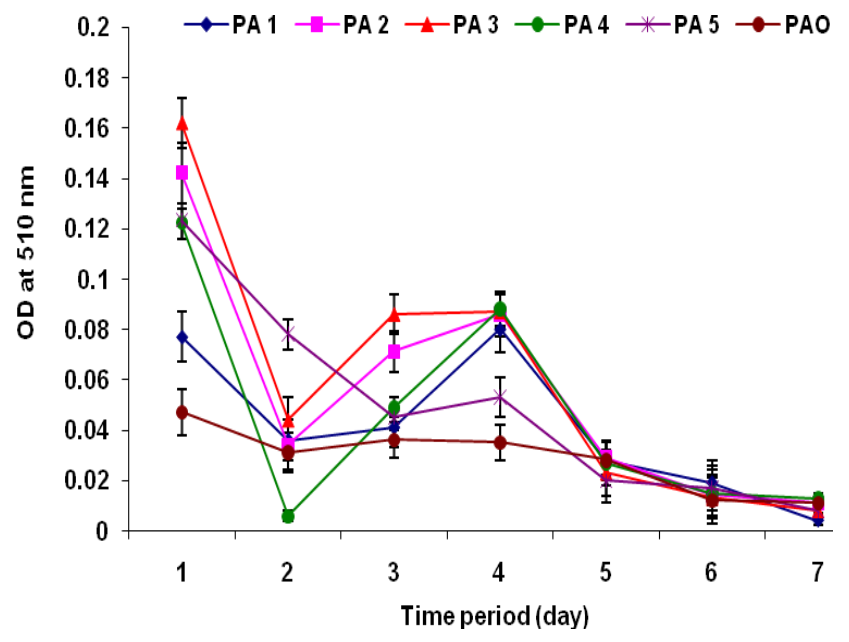

B.

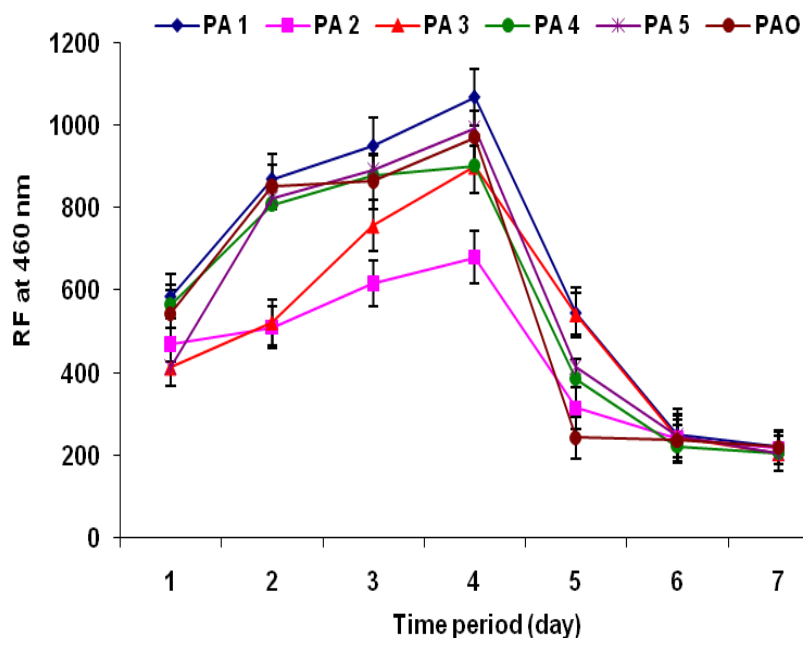

Fig. 7. Pyochelin (A) and pyoverdin (B) production by biofilm cells of $P$. aeruginosa.

Am. J. Biomed. Sci. 2009, 1(3), 178-187; doi: 10.5099/aj090300178
A.

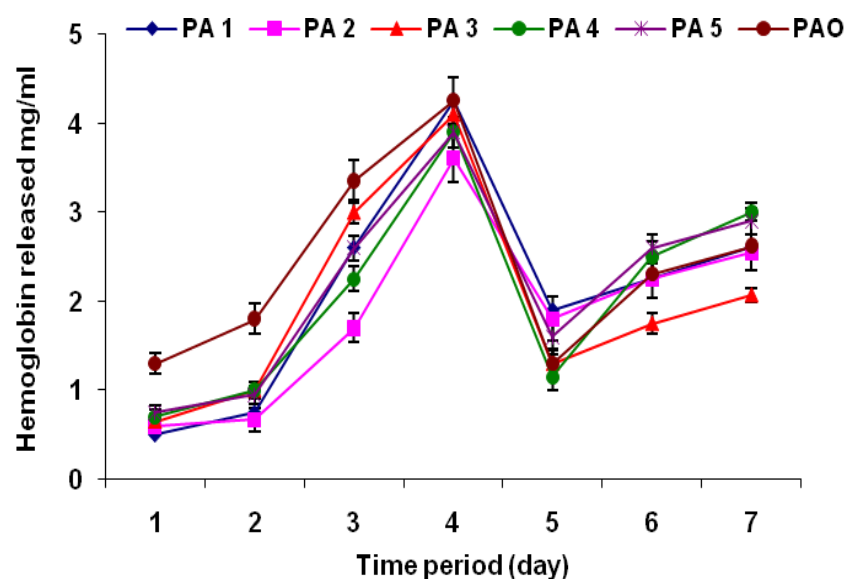

B.

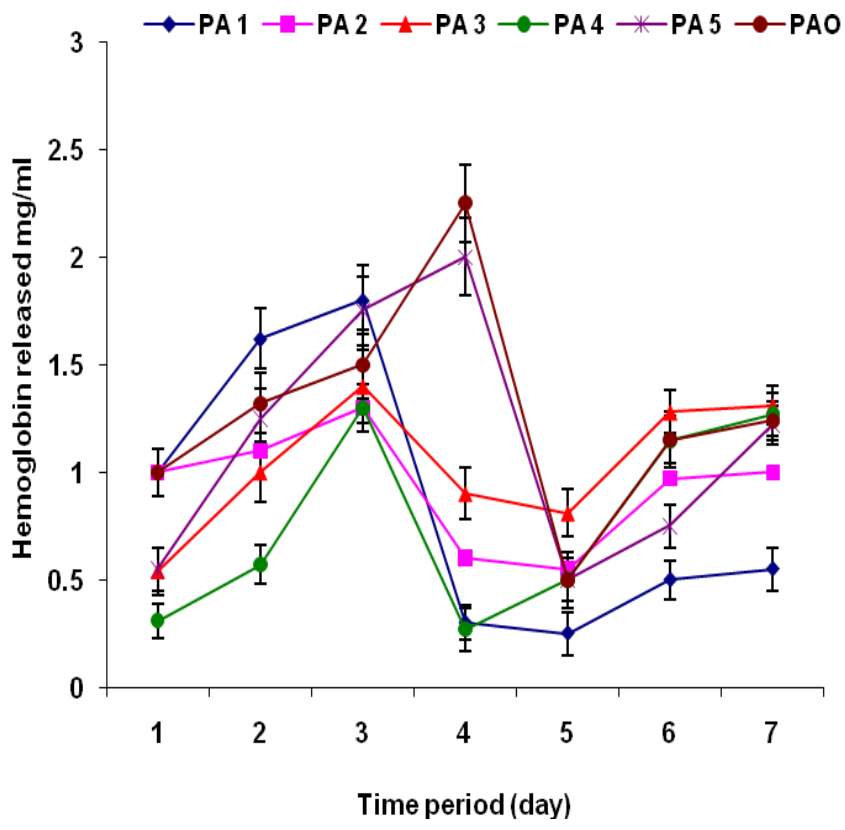

Fig. 8. Cell free (A) and cell bound hemolysin (B) production by biofilm cells of $P$. aeruginosa.

\section{Discussion}

UTIs are one of the most common infections affecting humans throughout their life span. Catheter-associated urinary tract infections (CAUTIs) represent the most common type of nosocomial infection and are a major health concern due to the complications and frequent recurrence [28]. $P$. aeruginosa is the most common pathogen causing hospital acquired CAUTIs. The catheterized urinary tract provides 
ideal conditions for the development of enormous biofilm populations [29]. This biofilm formation is a crucial factor in the development and persistence of infectious diseases caused by $P$. aeruginosa [30]. This pathogen has a basic survival strategy to colonize surfaces and grow as biofilm communities embedded in a gel-like polysaccharide matrix [31]. This extracellular matrix of biofilms of $P$. aeruginosa has been the subject of detailed study by many workers [3234]. It has been stressed that matrix provides a barrier leading to enhanced resistance to host defense mechanisms as well as to antibiotics causing treatment failure and also promote adherence to epithelial cells [35-38]. This extracellular matrix of glycocalyx in the form of exopolysaccharide of biofilms of $P$. aeruginosa is mainly composed of alginate. Alginate is an acetylated polymer of beta- D- mannouronic acid and alpha-L- guluronic acids where two uronic acids are arranged in different ways to form block structures [39-40]. Interestingly, in the present study, in biofilm cells a fall in the quantity of alginate was observed $5^{\text {th }}$ day onwards. No precise explanation for this change was obvious but in an earlier study of Boyd and Chakrabarty, [41], $P$. aeruginosa was demonstrated to produce alginate lyase, an enzyme involved in degradation of alginate. Repeatable pattern of cell death and lysis was shown to occur in biofilms of $P$. aeruginosa during the normal course of development. During the onset of biofilm development and biofilm killing thereafter, a bacteriophage capable of superinfecting and lysing the $P$. aeruginosa parent strain was detected in the fluid effluent from the biofilm [42, 43]. The bacteriophage implicated in biofilm killing was closely related to the filamentous phage Pf1 which existed as a prophage within the genome of $P$. aeruginosa. They proposed that prophage-mediated cell death could be an important mechanism of differentiation inside microcolonies that facilitate dispersal of a subpopulation of surviving cells. In another study of Hall-Stoodley and Stoodley, [44] biofilm development was shown to be a dynamic process of growth and detachment (or shedding) of bacterial cells and aggregates where detachment helps bacteria to colonize new niches before space and nutrients become limited hence leading to spread of infection.

In the present study, production of virulence factors by immature and mature biofilms was compared. Significant increase in the production of all the virulence factors was observed with increase in days of biofilm generation from day 1 to day 4. However, a significant decrease in production of all the virulence factors was observed in 5 day old biofilms. In addition, maximum cell count was observed in 5 day old followed by a slight decrease in 6 and 7 day old biofilms of $P$. aeruginosa which correlated with decrease in production of virulence factors. There is paucity of literature in relation to growth and elaboration of virulence factors by biofilm cells of $P$. aeruginosa isolated from UTI patients. However, reports are available in relation to other uropathogens. Ando et al., [45] correlated biofilmforming capacities of methicillin-resistant Staphylococcus aureus (MRSA) isolated from catheter related UTI cases with the presence of virulence determinants like $\alpha$-hemolysin, $\beta$ hemolysin and fibronectin binding protein and their gene products, $h l a, h l b, f n b A$ respectively by polymerase chain reaction (PCR) assay. In order to understand biofilm formation and pathogenicity of MRSA infection in the urinary tract, it was highlighted that during cell to cell interactions in biofilm formation, the level of hemolysin correlated with the level of biofilm formation [46]. Similarly, ability of Enterococcus faecalis isolates to form biofilms in vitro was considered as a marker of virulence trait that enhanced the ability of this pathogen to cause catheter related infections [47]. Potential relationship between biofilm formation and genes encoding virulence factors like hemolysin, enterococcal surface protein and gelatinase in E. faecalis isolates from catheter-related UTIs was also highlighted by Seno et al., [48]. In the present study also 4 day old biofilm cells of uroisolates of $P$. aeruginosa were elaborating quantitatively greater amounts of almost all the virulence factors. However, on further incubation beyond 4 days leading to formation of mature biofilms, a decrease in elaboration of all the virulence factors was observed. This ability to down regulate the production of virulence determinants may be a 
novel strategy employed by mature biofilms of $P$. aeruginosa to evade host immune defense mechanisms. The majority of $P$. aeruginosa strains isolated from the lungs of cystic fibrosis (CF) patients have also been shown to produce low levels of virulence determinants corroborating with the results of the present study [7, 49-51]. It has been demonstrated that although high levels of neutralizing antibodies are circulating in the cystic fibrosis patients but they fail to kill the bacteria [52]. It is possible that by decreasing the production of virulence traits, against which these antibodies are directed, may help this pathogen to avoid killing. This ability of biofilms of $P$. aeruginosa to regulate the production of virulence factors thereby becoming less pathogenic, may allow the host, and thus the bacteria, to survive for a longer period of time. This may help in persistence of this pathogen inside the host leading to recurrence and chronicity of infection. Studies with more strains of $P$. aeruginosa isolated from UTI patients are thus warranted to prove potential relationship between biofilm formation and expression of different virulence genes.

\section{References}

1. Saint, S.; Chenoweth, C.E. Biofilms and catheter-associated urinary tract infections. Infect Dis Clin North Am, 2003, 17, 411-432.

2. Jarvis, W.R.; Martone, W.J. Predominant pathogens in hospital infections. J Antimicrob Chemother, 1992, 29, 19-24.

3. Matheson, N.R.; Potempa, J.; Travis, J. Interaction of a novel form of Pseudomonas aeruginosa alkaline protease (aeruginolysin) with interleukin-6 and interleukin-8. Biol Chem, 2006, 387, 911-915.

4. Yates, S.P.; Jorgensen, R.; Andersen, G.R.; Merrill, A.R. Stealth and mimicry by deadly bacterial toxins. Trends Biochem Sci, 2006, 31, 123-133.

5. Zulianello, L.; Canard, C.; Kohler, T.; Caille, D.; Lacroix, J.S.; Meda, P. Rhamnolipids are virulence factors that promote early infiltration of primary human airway epithelia by Pseudomonas aeruginosa. Infect Immun, 2006, 74, 3134-3147.
6. Girard, G.; Bloemberg, G.V. Central role of quorum sensing in regulating the production of pathogenicity factors in Pseudomonas aeruginosa. Future Microbiol, 2008, 3, 97106.

7. Woods, D.E.; Schaffer, M.S.; Rabin, H.R.; Campbell, G.D.; Sokol, P.A. Phenotypic comparison of Pseudomonas aeruginosa strains isolated from a variety of clinical sites. J Clin Microbiol, 1986, 24, 260-264.

8. Woods, D.E.; Lam, J.S.; Parenchych, W.; Speet, D.P.; Campbell, M.; Godfrey, A.J. Correlation of virulence factors from clinical and environmental isolates with pathogenicity in the neutropenic mouse model. Can J Microbiol, 1997, 43, 541-551.

9. Lysczak, J.B.; Cannon, C.L.; Pier, G.B. Establishment of Pseudomonas aeruginosa infection: lessons from a versatile opportunist. Microbes Infect, 2000, 2, 1051-1060.

10. Vance, R.E.; Rietsch, A.; Mekalanos, J.J. Role of the type III secreted exoenzymes S, T, and $\mathrm{Y}$ in systemic spread of Pseudomonas aeruginosa $\mathrm{PAO} 1$ in vivo. Infect Immun, 2005, 73, 1706-1713.

11. Smith, D.C.; Spooner, R.A.; Watson, P.D.; Murray, J.L.; Hodge, T.W.; Amessou, M.; Johannes, L; Lord, J.M.; Roberts, L.M. Internalized Pseudomonas exotoxin A can exploit multiple pathways to reach the endoplasmic reticulum. Traffic, 2006, 7, 379393.

12. Hoiby, N.; Johansen, H.K.; Moser, C.; Sang, Z.; Ciofu, O.; Kharazmi, A. Pseudomonas aeruginosa and the in vitro and in vivo biofilm mode of growth. Microbe Infect, 2001, 3, 2335.

13. Klausen, M.; Aaes-Jorgensen, A.; Molin, S.; Tolker-Nielsen, T. Involvement of bacterial migration in the development of complex multicellular structures in Pseudomonas aeruginosa biofilms. Mol Microbiol, 2003, 50, 61-68.

14. Kuchma, S.L.; Connoly, J.P.; O’Toole, G.A. A three-component regulatory system regulates biofilm maturation and type III secretion in Pseudomonas aeruginosa. J Bacteriol, 2005, 187, 1441-1454.

15. Donlan, R.M. Biofilm formation: A clinically 
relevant microbiological process. Clin Infect Dis, 2001, 33, 1387-1392.

16. Drenkard, E. Antimicrobial resistance of Pseudomonas aeruginosa biofilms. Microbes Infect, 2003, 5, 1213-1239.

17. Boles, B.R.; Thoendel, M.; Singh, P.K. Selfgenerated diversity produces "insurance effects" in biofilm communities. Proc Natl Acad Sci USA, 2004, 101, 16630-16635.

18. Mittal, R.; Sharma, S.; Chhibber, S.; Harjai, K. In vitro effect of urinary constituents on the adhesion ability of Pseudomonas aeruginosa to human uroepithelial cells. $J$ Adhesion Science Technol 2009, In Press.

19. Mittal, R.; Sharma, S.; Chhibber, S.; Harjai, K. Contribution of free radicals to Pseudomonas aeruginosa induced acute pyelonephritis. Microb Pathog, 2008. 45, 323-330.

20. Mittal, R.; Sharma, S.; Chhibber, S.; Harjai, K. Iron dictates the virulence of Pseudomonas aeruginosa in urinary tract infections. $J$ Biomed Sci, 2008. 15, 731-741.

21. Harjai, K.; Mittal, R.; Chhibber, S.; Sharma, S. Contribution of Tamm-Horsfall protein to virulence of Pseudomonas aeruginosa in urinary tract infection. Microbes Infect, 2005, 7, 132-137.

22. Ladd, T.I.; Schmiel, D.; Nickel, J.C. The use of a radiorespirometric assay for testing the antibiotic sensitivity of catheter associated bacteria. J Urol, 1987, 138, 1451-1456.

23. Mittal, R.; Chhibber, S.; Sharma, S.; Harjai, K. Macrophage inflammatory protein-2, neutrophil recruitment and bacterial persistence in an experimental mouse model of urinary tract infection. Microbes Infect, 2004, 6, 1326-1332.

24. Walker, T.S.; Tomlin, K.L.; Worthen, G.S.; Poch, K.R.; Lieber, J.G.; Saavedra, M.T.; Fessler, M.B.; Malcolm, K.C.; Vasil, M.L.; Nick, J.A. Enhanced Pseudomonas aeruginosa biofilm development mediated by human neutrophils. Infect Immun, 2005, 73, 36933701.

25. Mathee, K.; Ciofu, O.; Sternberg, G.; Campbell, J.I.A. Mucoid conversion of Pseudomonas aeruginosa by $\mathrm{H} 2 \mathrm{O} 2$ : a mechanism for virulence activation in the cystic fibrosis lung. Microbiology, 1999, 145, 1349-1357.

26. Visca, P.; Chiarini, F.; Mansi, A.; Vetriani, C.; Serino, L.; Orsi, N. Virulence determinants in Pseudomonas aeruginosa strains from urinary tract infections. Epidemiol Infect, 1992, 108, 323-336.

27. Linkish, P.G.; Vogt, W. Direct hemolysin activity of phopholipase-A. Biochem Biophys Acta, 1972, 270, 241-250.

28. Morris, N.S.; Stickler, D.J.; McLean, R.J. The development of bacterial biofilms on indwelling urethral catheters. World J Urol, 1999, 17, 345-350

29. Nicolle, L.E. Catheter-related urinary tract infection. Drugs Aging, 2005, 22, 627-639

30. Driscoll, J.A.; Brody, S.L.; Kollef, M.H. The epidemiology, pathogenesis and treatment of Pseudomonas aeruginosa infections. Drug, 2007, 67, 351-358.

31. Hoiby, N.; Krogh Johansen, H.; Moser, C.; Song, Z.; Ciofu, O.; Kharazmi, A. Pseudomonas aeruginosa and the in vitro and in vivo biofilm mode of growth. Microbes Infect, 2001, 3, 23-35.

32. O'Toole, G.; Kaplan, H.B.; Kolter, R. Biofilm formation as microbial development. Ann Rev Microbiol, 2000, 54, 49-79.

33. Mah, T.F.; Pitts, B.; Pellock, B.; Walker, G.C.; Stewart, P.S.; O'Toole, G.A. A genetic basis for Pseudomonas aeruginosa biofilm antibiotic resistance. Nature, 2003, 426, 306310.

34. Allison, D.G. The biofilm matrix. Biofouling, 2003, 19, 139-150.

35. Walter, M.C. 3rd.; Roe, F.; Franklin, M.J.; Stewart, P.S. Contribution of antibiotic penetration, oxygen limitation, and loe metabolic activity to tolerance of Pseudomonas aeruginosa biofilms to ciprofloxacin and tobramycin. Antimicrob Chemother, 2003, 47, 317-323.

36. Costerton, W.; Veeh, R.; Shirtliff, M.; Pasmore, M.; Post, C.; Ehrlich, G. The application of biofilm science to the study and control of chronic bacterial infections. J Clin Investigation, 2003, 112, 1466-1477.

37. Jackson, K.D.; Starkey, M.; Kremer, S.; Parsek, M.R.; Wozniak, D.J. Identification of 
psl, a locus encoding a potential exopolysaccharide that is essential for Pseudomonas aeruginosa PAO1 biofilm formation. J Bacteriol, 2004, 186, 4466-4475.

38. Bagge, N.; Schuster, M.; Hentzer, M.; Ciofu, O.; Givskov, M.; Greenberg, E.P.; Hoiby, N. Pseudomonas aeruginosa biofilms exposed to imipenem exhibit changes in global gene expression and beta-lactamase and alginate production. Antimicrob Agents Chemother, 2004, 48, 1175-1187.

39. Evans, L.R.; Linker, A. Production and characterization of the slime polysaccharide of Pseudomonas aeruginosa. J Bacteriol, 1973, 116, 915-924.

40. Russell, N.J.; Gausa, P. Chemistry and biology of the alginate of mucoid strains of Pseudomonas aeruginosa in cystic fibrosis. Mol Aspates Med, 1988, 10, 1-91.

41. Boyd, A.; Chakrabarty, A.M. Role of alginate lyase in cell detachment of Pseudomonas aeruginosa. Appl Environ Microbiol, 1994, 60, 2355-2359.

42. Webb, J.S.; Lau, M.; Kjelleberg, S. Bacteriophage and phenotypic variation in Pseudomonas aeruginosa biofilm development. J Bacteriol, 2004, 186, 80668073.

43. Rice, S.A.; Tan, C.H.; Mikkelsen, P.J.; Kung, V.; Woo, J.; Tay, M.; Hauser, A.; McDougald, D.; Webb, J.S.; Kjelleberg, S. The biofilm life cycle and virulence of Pseudomonas aeruginosa are dependent on a filamentous prophage. ISME J, 2009, 3, 271-282.

44. Hall-Stoodley, L.; Stoodley, P. Biofilm formation and dispersal and the transmission of human pathogens. Trends Microbiol, 2005, 13, 7-10.

45. Ando, E.; Monden, K.; Mitsuhata, R.; Kariyama, R.; Kumon, H. Biofilm formation among methicillin-resistant Staphylococcus aureus isolates from patients with urinary tract infection. Acta Med Okayama, 2004, 58, 207 214.

46. Caiazza, N.C.; O'Toole G.A. Alpha toxin is required for biofilm formation by Staphylococcus aureus. J Bacteriol, 2003, 185, 3214-3217.

47. Sandoe, J.A.T.; Witherden, I.R.; Cove, J.R.; Heritage, J.; Wilcox, M.H. Correlation between enterococcal biofilm formation in vitro and medical-device-related infection potential in vivo. J Med Microbiol, 2003, 52, 547-550.

48. Seno, Y.; Kariyama, R.; Mitsuhata, R.; Monden, K.; Kumon, H. Clinical implications of biofilm formation by Enterococcus faecalis in the urinary tract. Acta Med Okayama, 2005, 59, 79-87.

49. Burke, V.; Robinson, J.O.; Richardson, C.J.L.; Bundell, C.S. Longitudinal studies of virulence factors of Pseudomonas aeruginosa in cystic fibrosis. Pathology, 1991, 23, 145-148

50. Jaffar-Bandjee, M.C.; Lazdunski, A.; Bally, M.; Carrère, J.; Chazalette, J.P.; Galabert, C. Production of elastase, exotoxin A, and alkaline protease in sputa during pulmonary exacerbation of cystic fibrosis in patients chronically infected by Pseudomonas aeruginosa. J Clin Microbiol, 1995, 33, 924929.

51. Woods, D. E.; Sokol, P. A.; Bryan, L. E.; Storey, D. G.; Mattingly, S. J.; Vogel, H. J.; Ceri, H. In vivo regulation of virulence in Pseudomonas aeruginosa associated with genetic rearrangement. J Infect Dis, 1991, 163, 143-149.

52. Hollsing, A.E.; Granström, M.; Vasil, M.L.; Wretlind, B.; Strandvik, B. Prospective study of serum antibodies to Pseudomonas aeruginosa exoproteins in cystic fibrosis. $J$ Clin Microbiol, 1987, 25, 1868-1874. 